\title{
The effect of an inversion system and the time interval between matings on postcopulatory sexual selection in the seaweed fly, Coelopa frigida
}

\author{
JE Blyth ${ }^{1}$ and AS Gilburn ${ }^{1,2}$ \\ ${ }^{1}$ Department of Biology, University of Leicester, Leicester LE1 7RH, UK; ${ }^{2}$ School of Biological and Environmental Sciences, University of \\ Stirling, Stirling FK9 4LA, UK
}

\begin{abstract}
The seaweed fly, Coelopa frigida, exhibits LMSP. A large chromosomal inversion system affects many traits including egg-to-adult viability via heterosis. Consequently, there is also considerable potential for cryptic female mate choice to operate on the basis of sperm karyotype. Here, we investigated the effect of time interval and chromosomal inversion karyotype on postcopulatory sexual selection. Homokaryotypic females were mated with a male of the same and a male of the opposite homokaryotype. The order of the matings was varied so cryptic female mate choice could operate either in concert or antagonistically with LMSP. LMSP was found when there was a $24 \mathrm{~h}$ time interval between matings, irrespective of the order in which the males
\end{abstract}

were mated. However, when the males were mated in quick succession the order of mating was important. When LMSP and cryptic female mate choice work in concert a high level of LMSP was found. However, when the male of opposite homokaryotype mated first, then first male sperm precedence was observed. This suggests that polyandrous females might be able to bias paternity but only when matings occur in quick succession. Consequently, population density is likely to affect the operation of postcopulatory sexual selection.

Heredity (2005) 95, 174-178. doi:10.1038/sj.hdy.6800713; published online 6 July 2005

Keywords: sperm competition; cryptic female mate choice; heterosis; chromosomal inversion system

\section{Introduction}

Postcopulatory sexual selection has been found to be an increasingly important force shaping the evolution of mating systems (Birkhead and Pizzari, 2002). There are two main components of postcopulatory sexual selection: (1) sperm competition (Parker, 1970; Birkhead and Møller, 1998) and (2) cryptic female mate choice (Thornhill, 1983; Eberhard, 1996). Sperm competition selects on the basis of the relative ability of the sperm of different males to successfully fertilise eggs after copulation (Parker, 1998). Sperm competition has been found to be prevalent in many taxa (Birkhead and Møller, 1998). It is common in insects (Simmons and Siva-Jothy, 1998), often being reported in the form of last male sperm precedence (LMSP).

The extent of LMSP has traditionally been measured using $P_{2}$ values, the mean proportion of eggs fertilised by the second of two males that mate with a female (Boorman and Parker, 1976). Variation in $P_{2}$ values has predominantly been ascribed to sperm competition in many studies (Birkhead and Hunter, 1990; Simmons and Siva-Jothy, 1998). Investigations into variation in $P_{2}$ values can reveal the mechanisms controlling sperm precedence. Various factors have been found to affect $P_{2}$ values in

Correspondence: AS Gilburn, School of Biological and Environmental Sciences, University of Stirling, Cottrell Building, Stirling FK9 4LA, UK. E-mail: andre.gilburn@stir.ac.uk

Received 2 November 2004; accepted 14 June 2005; published online 6 July 2005 insects including relative body size of the two males, mating order, the relative duration of copulation, the number and size of sperm transferred and the previous mating history of the males (reviewed in Simmons, 2001). Simmons also reviewed the effect of altering the time interval between matings, revealing that in the majority of insects, $P_{2}$ values increase with longer intervals between matings. In many insects this probably occurs as a result of sperm loss over time from the females' spermathecae (Yamagishi et al, 1992; Colegrave et al, 1995).

Cryptic female mate choice occurs when females can influence which male's sperm fertilizes their eggs after mating. Evidence of cryptic female mate choice has been found in several insect taxa (Otronen, 1997; Johnson et al, 1999; Ward, 2000; Tallamy et al, 2002). Males have been found to be able to influence cryptic female mate choice in some insects, by tapping the female's genitalia (Otronen, 1997) and stroking the female with their antennae (Tallamy et al, 2002). Cryptic female mate choice and sperm competition may well act in concert, for example, males that are better sperm competitors also produce fitter offspring in the yellow dung fly, Scathophaga stercoraria (Hosken et al, 2003).

The seaweed fly (Diptera: Coelopidae) mating system is characterised by extreme sexual conflict, with females performing violent mate rejection responses when mounted by males (Day and Gilburn, 1997). Variation in the ability of females to reject males of different sizes results in sexual selection for large male size (Crean and Gilburn, 1998; Crean et al, 2000). Male mate choice also operates on the basis of female fecundity (Pitafi et al, 
1990) and longevity (Dunn et al, 2001). LMSP has been previously reported in Coelopa frigida with $P_{2}$ values increasing with the time interval between matings (Butlin, 1983). Population density varies enormously between populations, with females likely to mate with hundreds of males during their lifespan in high-density populations (Blyth and Gilburn, unpublished), providing ample opportunity for sperm competition and cryptic female mate choice to operate. Females in lower density populations are likely to have lower levels of polyandry, and perhaps mate only once or twice between egg clutches. Collections of females from some very lowdensity populations have revealed that the majority were actually unmated (Gilburn, unpublished data).

The $C$. frigida genome contains several inversion systems, including one very large inversion on chromosome I that has numerous effects on fitness traits. There are two forms of the inversion, known as $\alpha$ and $\beta$. The $\alpha \alpha$ homokaryotypes are large, develop slowly (Day et al, 1980) and suffer relatively high levels of egg-to-adult mortality (Butlin et al, 1984; Butlin and Day, 1985). The $\beta \beta$ homokaryotypes are small, develop quickly and suffer intermediate levels of egg-to-adult mortality. The heterokaryotypes are intermediate in size, have an intermediate development time and exhibit the highest egg-to-adult survival rates. The effects of the inversion are much more exaggerated in males than in females. Typically an excess of heterokaryotypes is found, ranging from 10 to $40 \%$ (Butlin et al, 1982; Day et al, 1983). Laboratory experiments and field samples revealed that the level of heterozygote excess increased with larval density (Butlin et al, 1984). In wild populations the frequency of $\alpha \alpha$ homokaryotypes ranges from 5 to $20 \%$, the frequency of $\beta \beta$ homokaryotypes ranges from 15 to $40 \%$ and the frequency of the heterokaryotypes ranges from 50 to $70 \%$ (Day et al, 1983). Homokaryotypic females in highdensity populations are likely to mate with males of all three inversion karyotypes between oviposition events.

This inversion system provides a considerable selective advantage for females to exhibit mate choice on the basis of male karyotype in order to produce heterokaryotypic offspring. Several studies have failed to find evidence of precopulatory female mate choice in order to increase production of heterokaryotypic offspring (Gilburn et al, 1992; Crean and Gilburn, 1998; Crean et al, 2000). Furthermore, the karyotype of a female does not influence whether or not a male will attempt to mate with her (Gilburn, unpublished data), thus disassortative mating also does not occur via male mate choice. In fact, precopulatory sexual selection appears to occur as a side effect of sexual conflict with large males gaining an advantage through their greater ability to withstand violent female rejection responses (Gilburn et al, 1992; Crean and Gilburn, 1998; Crean et al, 2000). However, a previous study investigating paternity of wild flies suggested the production of an excess of heterokaryotypic offspring (Day and Butlin, 1987).

Postmating paternity biases with respect to chromosomal karyotypes have been previously identified in another insect species, Podisma pedestris, within a hybrid zone (Hewitt et al, 1987, 1989). This species shows no evidence of assortative mating within the hybrid zone. However, an excess of homozygote offspring were produced by females that were mated with males of the same and different racial karyotypes. The order that the males mated affected the $P_{2}$ value with first male sperm precedence generally observed. Thus, postcopulatory sexual selection has been found to occur on the basis of chromosomal karyotypes, in the absence of precopulotory sexual selection. Similar paternity biases might occur in C. frigida, although in this species it is predicted that biases should favour the production of heterokaryotypic rather homokaryotypic offspring.

Here we determine if postcopulatory sexual selection might operate on the basis of the chromosome I inversion system and generate an excess of heterokaryotypic offspring. We also determine if the order of matings and the time interval between matings affects $P_{2}$ value.

\section{Materials and methods}

The adults used had been stored for between 1 and 2 weeks at $5{ }^{\circ} \mathrm{C}$ prior to the study. Virgin females from an $\alpha$ and a $\beta$-homokaryotypic line were placed with two males consecutively until they mated with each male for up to $5 \mathrm{~min}$. Copulations typically last between 1 and $2 \mathrm{~min}$ but occasionally continue for longer. Males were stopped from mating for longer than 5 min to limit any possibility that variation in fertilisation success might be associated with copulation duration, although previous studies have revealed no such correlation (Pitafi, 1991). The matings were carried out in $1.5 \mathrm{ml}$ microcentrifuge tubes to reduce the ability of females to successfully reject males. One of the males was of the same line as the female and the other from the line of opposite homokaryotype. The order in which the two males were mated to the female was varied. In addition, we also varied the time interval between matings. The second male was either introduced to the female immediately after the first male had finished mating or after a period of $24 \mathrm{~h}$. These time intervals were chosen to simulate the interval between matings in high- and low-density populations. After the second mating, females were placed individually in pots of minced seaweed (consisting of mixed Fucus and Laminaria species) to lay eggs until death. Oviposition is stimulated by the presence of seaweed but not mating (Dunn et al, 2002), so the females were maintained with sucrose solution as a source of energy and water to prevent oviposition in the intervening period when there was a $24 \mathrm{~h}$ gap between matings. The larvae of each female were allowed to develop to adulthood before being collected and frozen. The inversion karyotypes of the female offspring were determined using starch gel electrophoresis and staining for Adh alleles (Day et al, 1982). This has been successfully used as a marker for inversion karyotype in many previous studies (Gilburn et al, 1992, 1993, 1996). Only female offspring were scored to minimise the effects of heterosis (which has a much greater effect on egg-toadult survival of males). Families that contained less than 10 female offspring were disregarded. In all, 42 families were included in the data set. The inversion karyotype of 1909 female offspring was determined.

\section{Analysis}

The data were analysed using generalised linear models of the number of offspring fathered by the two males. A binomial error distribution was used. This generated considerable overdispersion. $F$-values were adjusted by the overdispersion parameter in all models. AIC was 
used to generate the models of best fit. In both models all terms were retained. A GLM with a normal error distribution was used to model the total number of offspring produced by each female.

\section{Results}

The inversion karyotype of the female did not affect $P_{2}$ value $\left(F_{1,34}=0.00, P=0.99\right)$, nor did the karyotype of the second male $\left(F_{1,34}=1.17, P=0.29\right)$. There was also no association between time interval between matings and $P_{2}$ value $\left(F_{1,34}=0.33, P=0.57\right)$. There were no significant two-way interaction terms. However, there was a significant three-way interaction term between the karyotype of the female, the karyotype of the second male and the time interval between matings $\left(F_{1,34}=5.69\right.$, $P=0.023$ ).

As neither female karyotype nor the karyotype of the second male directly affected $P_{2}$ value, we simplified the analysis by pooling the data for the two female homokaryotypes. The data were then analysed using a new independent variable, the order of matings (whether the second male was of the opposite or same homokaryotype as the female). This model showed that neither the time interval between matings $\left(F_{1,38}=0.08\right.$, $P=0.79)$ nor the order of matings $\left(F_{1,38}=2.36, P=0.13\right)$ affected $P_{2}$ value. However, a significant interaction term $\left(F_{1,38}=5.40, P=0.013\right)$ was found between time interval and order of matings with lower $P_{2}$ values found when the second male was of the same homokaryotype as the female and the second mating immediately followed the first. Indeed, $P_{2}$ values below $50 \%$ (first male sperm precedence) were typically found when the first male was of the opposite karyotype of the female and the second mating immediately followed the first (Figure 1).

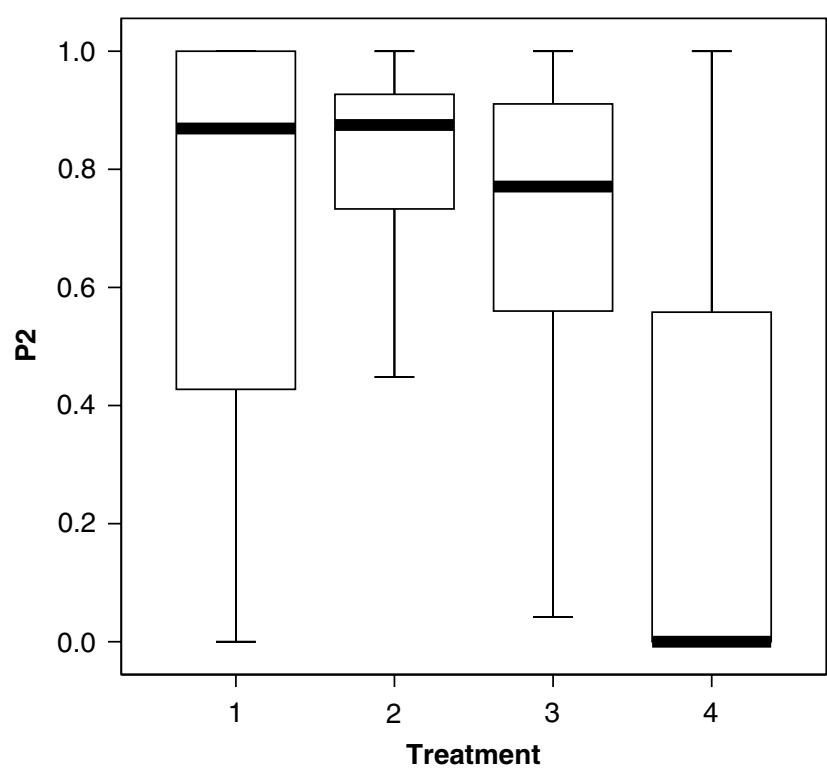

Figure 1 A box plot showing the median, quartiles and range of the $P_{2}$ values for the offspring of females separated by the time interval between matings and whether the second male was of the same or opposite karyotype. Treatment 1 (24h, opposite); treatment 2 (immediate, opposite); treatment 3 (24h, same); treatment 4 (immediate, same).
Neither the inversion karyotype of the female $\left(F_{1,34}=0.01, P=0.92\right)$, nor the karyotype of the first male $\left(F_{1,34}=0.01, P=0.92\right)$ was associated with the number of female offspring produced. There was also no association between time interval between matings and number of female offspring produced $\left(F_{1,34}=1.01, P=0.32\right)$. In addition, there were no significant interaction terms associated with the number of female offspring.

\section{Discussion}

The results of this study revealed that the time interval and order of polyandrous copulations with males of different chromosomal karyotypes interacted in their effects on $P_{2}$ value in C. frigida. First male sperm precedence occurs when males mate in rapid succession and the second male has the same inversion karyotype as the female. Whereas, there is a consistent finding of LMSP when there is a 24-h time interval between matings, regardless of the mating order, suggesting that sperm loss probably occurs from the female within $24 \mathrm{~h}$ of mating, as has been found in other insect species (Yamagishi et al, 1992; Colegrave et al, 1995). This is not surprising in a species in which females may mate up to 30 times a day in high-density populations (Blyth and Gilburn, unpublished results). It is also possible that $C$. frigida sperm are very short lived due to LMSP and high levels of polyandry, although this seems unlikely as they are also found at very low densities.

Previous studies have found that large males gain a mating advantage (Gilburn et al, 1992; Crean and Gilburn, 1998; Crean et al, 2000). This occurs as a result of their superior ability to overcome female resistance. Male size is largely determined by inversion karyotype, thus differences in size between males of the two homokaryotypes could have affected the results. However, as male karyotype did not directly affect $P_{2}$ value, differences in the size of males of different karyotypes did not seem to influence $P_{2}$ value.

The finding that the pattern of paternity biases varies with the time interval between matings suggests that population density may have a major effect on the postcopulatory sexual selection. Population density will determine the level of polyandry. At higher densities the time interval between matings will be shorter, resulting in greater potential for adaptive paternity biases. In lower density populations LMSP would be expected to be more common. Thus, adaptive paternity biases would be expected to contribute more to the heterokaryotypic excess in higher density populations. There is a greater heterokaryotypic excess in high-density populations; however, this has previously been assumed to be associated with increased egg-to-adult viability of heterokaryotypes at higher larval density (Butlin et al, 1982, 1984; Day et al, 1983). Thus, we provide here an additional explanation for the association between density and heterokaryotype excess. The relative importance of these two mechanisms in generating the excess of heterokaryotypes can be determined experimentally as the extent of postcopulatory sexual selection should be dependent upon adult density, whereas variation in the relative egg-to-adult viabilities of the different karyotypes should be dependent upon larval density. 
It should also be noted that heterosis might have increased the number of heterokaryotypic offspring in all treatments. We maintained the larval at low density and only used female offspring to minimise the effects of heterosis. Any heterosis that was present should not have affected our conclusions as its effects will have varied with neither the order in which the males were mated nor the time interval between matings.

It has been suggested that laboratory studies of postcopulatory sexual selection in which females only mate with two males test only a simple situation (Simmons, 2001). In many species, including C. frigida, females are known to mate with more than two males. Studies that have used more than two males have found evidence that LMSP may break down in some species (Zeh and Zeh, 1994; Radwan, 1997; Drnevich, 2003), although this is not always the case (Arnaud et al, 2001). We have estimated that some $C$. frigida females may mate with hundreds of different males during their lifespan (Blyth and Gilburn, unpublished results). Thus, our results should be treated with some caution until they have been repeated when females mate with many more than two males. This requires the development of a molecular marker system that will enable us to establish paternity from a larger number of males than is currently possible using the $A d h$ marker system.

Like most Diptera, female coelopids have multiple and complex spermathecae (McAlpine, 1991; Day and Gilburn, 1997). Female C. frigida typically have three spermathecae, so there is the potential for them to separate sperm from different males. In high-density populations, females are likely to mate with many more than three males so they could not use a separate spermatheca to store the sperm of each male, although, they could separate the sperm of males of the three inversion karyotypes.

The lack of any effects on the number of offspring produced by each female also gives some indication about the mechanism by which paternity biases might occur in this species. Clearly, females did not alter their oviposition rate in response to the order with which they mated with the two males, or to the time interval between matings. In other words, females do not increase their oviposition rate immediately after mating with a complementary male. This concurs with previous findings that seaweed alone stimulates female oviposition (Dunn et al, 2002).

Some of the best examples of paternity biases in insects come from species which exhibit copulatory courtship behaviour (Eberhard, 1996). Male coelopids rub the female's antennae with their forelegs both before and during copulation (Day et al, 1990). The functional significance of this behaviour is not clear, however, it might play a role in signalling to the female the inversion karyotype of the male. It is known that females that have had their antennae removed are less likely to mate (Day et al, 1990). It is also known that coating the male's prothoracic legs with enamel paint reduces their mating success.

We show here that LMSP occurs when matings are separated by a day. However, when males mate in rapid succession the chromosome I inversion karyotype of the male appears to determine the relative competitive ability of sperm from different males. Paternity biases occur favouring the use of sperm of the opposite homokaryotype, increasing the production of heterokaryotypic offspring, who have a substantial fitness advantage as a result of heterosis. Several previous studies of precopulatory sexual selection in coelopids have failed to find evidence of female mate choice on the basis of inversion karyotype, despite considerable indirect benefits to such choice. Here, we report evidence of postcopulatory sexual selection on this basis. This adds further weight to the growing importance of postcopulatory sexual selection as a major force shaping the evolution of mating systems.

\section{Acknowledgements}

We are grateful to Judy Jackson for providing technical support, to Roger Butlin for providing statistical advise and to Derek Dunn, Matt Tinsley and two anonymous referees for useful comments on the manuscript. This work was funded by an NERC studentship to JEB.

\section{References}

Arnaud L, Gage MJG, Haubruge E (2001). The dynamics of second- and third-male fertilization precedence in Tribolium castaneum. Entomol Exp Appl 99: 55-64.

Birkhead TR, Hunter FM (1990). Mechanisms of sperm competition. Trends Ecol Evol 10: 48-52.

Birkhead TR, Møller AP (1998). Sperm Competition and Sexual Selection. Academic Press: London.

Birkhead TR, Pizzari T (2002). Post-copulatory sexual selection. Nat Rev Genet 3: 262-273.

Boorman E, Parker GA (1976). Sperm (ejaculate) competition in Drosophila melanogaster, and the reproductive value of females to males in relation to female age and mating status. Ecol Entomol 1: 145-155.

Butlin RK (1983). The Maintenance of an Inversion Polymorphism in Coelopa frigida. PhD Thesis, University of Nottingham, Nottingham, UK.

Butlin RK, Day TH (1985). Adult size, longevity and fecundity in the seaweed fly, Coelopa frigida. Heredity 54: 107-110.

Butlin RK, Collins PM, Day TH (1984). The effect of larval density on an inversion polymorphism in the seaweed fly, Coelopa frigida. Heredity 52: 415-423.

Butlin RK, Collins PM, Skevington SJ, Day TH (1982). Genetic variation at the alcohol dehydrogenase locus in natural populations of the seaweed fly, Coelopa frigida. Heredity 48: 45-55.

Colegrave N, Birkhead TR, Lessells CM (1995). Sperm precedence in zebra finches does not require special mechanisms of sperm competition. Proc Roy Soc London B 259: 223-228.

Crean CS, Gilburn AS (1998). Sexual selection as a side effect of sexual conflict in the seaweed fly, Coelopa ursine. (Diptera: Coelopidae). Anim Behav 56: 1405-1410.

Crean CS, Dunn DW, Day TH, Gilburn AS (2000). Female mate choice for large males in several species of seaweed fly (Diptera: Coelopidae). Anim Behav 59: 121-126.

Day TH, Butlin RK (1987). Non-random mating in natural populations of the seaweed fly, Coelopa frigida. Heredity 58 213-220.

Day TH, Dawe C, Dobson T, Hillier PC (1983). A chromosomal inversion polymorphism in Scandanavian populations of the seaweed fly, Coelopa frigida. Hereditas 99: 135-145.

Day TH, Dobson T, Hillier PC, Parkin DT, Clarke BC (1980). Different rates of development associated with the alcohol dehydrogenase locus in the seaweed fly, Coelopa frigida. Heredity 44: 321-326.

Day TH, Dobson T, Hillier PC, Parkin DT, Clarke BC (1982). Non-random association of enzyme and chromosomal 
polymorphisms in the seaweed fly, Coelopa frigida. Heredity 48: 35-44.

Day TH, Foster SP, Engelhard G (1990). Mating behavior in seaweed flies. I Insect Behav 3: 105-120.

Day TH, Gilburn AS (1997). Sexual selection in seaweed flies. Adv Study Behav 26: 1-57.

Drnevich JM (2003). Number of mating males and mating interval affect last-male sperm precedence in Tenebrio molitor L. Anim Behav 66: 349-357.

Dunn DW, Crean CS, Gilburn AS (2001). Male mating preference for female survivorship in the seaweed fly Gluma musgravei. Proc Roy Soc London B 268: 1255-1258.

Dunn DW, Crean CS, Gilburn AS (2002). The effects of exposure to seaweed on willingness to mate, oviposition, and longevity in seaweed flies. Ecol Entomol 27: 554-564.

Eberhard WG (1996). Female Control: Sexual Selection by Cryptic Female Mate Choice. Princeton University Press: Princeton, New Jersey.

Gilburn AS, Foster SP, Day TH (1992). Female mate preference for large male size in Coelopa frigida. Heredity 69: 209-216.

Gilburn AS, Foster SP, Day TH (1993). Genetic correlation between female mating preference for large male size and the preferred male character in the seaweed fly, Coelopa frigida. Evolution 47: 1788-1795.

Gilburn AS, Crean CS, Day TH (1996). Sexual selection in natural populations of seaweed flies: variation in the offspring fitness of females carrying different inversion karyotypes. Proc Roy Soc London B 263: 249-256.

Hewitt GM, Nichols RA, Barton NH (1987). Homogamy in a hybrid zone in the alpine grasshopper Podisma pedestris Heredity 59: 457-466.

Hewitt GM, Mason P, Nichols RA (1989). Sperm precedence and homogamy across a hybrid zone in the alpine grasshopper Podisma pedestris. Heredity 62: 343-354.

Hosken DJ, Garner TWJ, Tregenza T, Wedell N, Ward PI (2003). Superior sperm competitors sire higher-quality young. Proc Roy Soc London B 270: 1933-1938.

Johnson JC, Ivy TM, Sakaluk SK (1999). Female remating propensity contingent on sexual cannibalism in sagebrush crickets, Cyphoderris strepitans: a mechanism of cryptic female choice. Behav Ecol 10: 227-233.
McAlpine DK (1991). Review of the Australian kelp flies (Diptera: coelopidae). Syst Entomol 16: 29-84.

Otronen MJ (1997). Sperm numbers, their storage and usage in the fly, Dryomiza anilis. Proc Roy Soc London B 264: 777-782.

Parker GA (1970). Sperm competition and its evolutionary consequences. Biol Rev Cam Phil Soc 45: 525-567.

Parker GA (1998). Sperm competition and the evolution of ejaculates: towards a theory base. In: Birkhead TR, Møller AP (eds) Sperm Competition and Sexual Selection. Academic Press: London. pp 3-54.

Pitafi KD (1991). Male Mate Choice in Seaweed Flies, Coelopa frigida. PhD Thesis, University of Nottingham, Nottingham, UK.

Pitafi KD, Simpson R, Stephen JJ, Day TH (1990). Adult size and mate choice in seaweed flies. Heredity 65: 191-197.

Radwan J (1997). Sperm precedence in the bulb mite, Rhizoglyphus robini: context-dependent variation. Ethol Ecol Evol 9: 373-383.

Simmons LW (2001). Sperm Competition and its Evolutionary Consequences in Insects. Princeton University Press: Princeton, New Jersey.

Simmons LW, Siva-Jothy MT (1998). Sperm competition in insects: mechanisms and the potential for selection. In: Birkhead TR, Moller AP (eds) Sperm Competition and Sexual Selection. Academic Press: London. pp 341-434.

Tallamy DW, Powell BE, McClafferty JA (2002). Male traits under cryptic female mate choice in the spotted cucumber beetle (Coleoptera: Chrysomelidae). Behav Ecol 13: 511-518.

Thornhill R (1983). Cryptic female mate choice and its implications in the scorpion fly, Harpobittacus nigriceps. Am Nat 122: 765-788.

Ward PI (2000). Cryptic female choice in the yellow dung fly, Scathophaga stercoraria. Evolution 54: 1680-1686.

Yamagishi M, Ito Y, Tsubaki Y (1992). Sperm competition in the melon fly, Bactrocera cucurbitae (Diptera, Tephritidae) - effects of sperm longevity on sperm precedence. J Insect Behav 5: 599-608.

Zeh JA, Zeh DW (1994). Last-male sperm precedence breaks down when females mate with three males. Proc Roy Soc London B 257: 287-292. 